\title{
A Minimal Harmonic Controller for a STATCOM
}

\author{
Ben-Sheng Chen and Yuan-Yih Hsu, Senior Member, IEEE
}

\begin{abstract}
In this paper, a novel controller with fixed modulation index (MI) and variable dc capacitor voltage reference to minimize voltage and current harmonics is presented for a distribution static synchronous compensator (STATCOM). The STATCOM with the proposed controller consists of a three-phase voltage-sourced inverter and a dc capacitor and is used to provide reactive power compensation and regulate ac system bus voltage with minimum harmonics. A systematic design procedure based on pole-zero cancellation, root locus method, and pole assignment method has been developed to determine proper parameters for the current regulator, the dc voltage controller, and the ac voltage controller of the STATCOM. With the proposed STATCOM controller, harmonic distortions in the inverter output current and voltage can be reduced since the $M I$ is held constant at unity in steady state. In addition, a fast adjustment in the STATCOM output reactive power is achieved to regulate the ac bus voltage through the adjustment of the dc voltage reference during the transient period. Simulation and experimental results for the steady-state operating condition and transient operating conditions for the system subjected to a reactive current reference step change, a three-phase line to neutral fault, and a step load change are presented to demonstrate the effectiveness of the proposed controller.
\end{abstract}

Index Terms-Fixed modulation index (MI), harmonics, pole assignment technique, root locus method, static synchronous compensator (STATCOM), variable dc voltage reference.

\section{INTRODUCTION}

$\mathbf{S}$ TATIC synchronous compensators (STATCOMs) have been applied to regulate bus voltage and to provide reactive power and power factor control in distribution and transmission systems in recent years [1]-[17]. Various STATCOM controllers with inner current regulator loop have been developed to achieve fast control of STATCOM output voltage and reactive power [3]-[9]. Johan and Frederik [10] analyzed the voltage harmonics generated by voltage-fed inverters using the pulsewidth modulation (PWM) technique.

In the literature, two typical control schemes have been proposed for STATCOMs [3]. In the phase angle control scheme [3], [7], only the phase angle $\alpha$ is employed as the control variable. The modulation index (MI) is held constant to avoid negative impacts on harmonics [3]. Thus, minimal harmonics in steady state can be reached by the phase angle control scheme since the MI is fixed. However, rapid adjustments in the reactive power output of the STATCOM cannot be achieved

Manuscript received March 25, 2005; revised October 12, 2007. This work was supported by the National Science Council of the Republic of China, under Contract NSC 93-2213-E-002-011.

B.-S. Chen is with Delta Electronics, Inc., Taipei 11491, Taiwan, R.O.C. (e-mail: d89921017@ntu.edu.tw).

Y.-Y. Hsu is with the Department of Electrical Engineering, National Taiwan University, Taipei 106, Taiwan, R.O.C. (e-mail: yyhsu@cc.ee.ntu.edu.tw).

Digital Object Identifier 10.1109/TIE.2007.896266 by the linear phase angle control [7] since reactive power is less sensitive to phase angle $\alpha$ than the voltage magnitude $|E|[18]$ and the STATCOM output voltage magnitude $|E|$ is held constant since both dc capacitor voltage reference $\left(\mathrm{Vdc}^{*}\right)$ and MI are kept constant in the linear $\alpha$ control scheme. To improve the response speed of the reactive power output $\mathrm{Q}$, a nonlinear controller that is able to achieve wide-range phase angle control has been proposed [3]. The nonlinear $\alpha$ controller in [3] employed the dc capacitor voltage Vdc and its reference value $\mathrm{Vdc}^{*}$ and the $q$-axis current $i_{q}$ and its reference $i_{q}^{*}$ as the controller inputs. Note that the $q$-axis current $i_{q}$ was employed as one of the controller inputs since it was directly related to the STATCOM reactive power output.

Since the MI cannot be adjusted in the $\alpha$ control schemes, the STATCOM output voltage $|E|$ and reactive power $Q$ cannot be modulated rapidly until the capacitor voltage $\mathrm{Vdc}$ is charged or discharged to a new level. This limits the response speed of the $\alpha$ control scheme to a great extent since a small dc capacitor that allows fast charging or discharging is usually unacceptable due to the associated high ripple voltages.

To improve the response speed of the STATCOM output voltage and reactive power, a control scheme, in which both the MI and the phase angle $\alpha$ are controlled, has been proposed [3]. Note that the dc capacitor voltage reference $\mathrm{Vdc}^{*}$ is held constant all the time in the MI- $\alpha$ control scheme [3]. Since the voltage magnitude $|E|$ can be adjusted rapidly through the adjustment of the MI, fast modulation of the STATCOM reactive power output can be achieved due to the high sensitivity of $Q$ with respect to $|E|$. However, the MI- $\alpha$ control scheme was not favored in [3] since the variable MI might have a negative impact on harmonic contents and others [3]. In this work, a novel control scheme with variable dc capacitor voltage reference $\mathrm{Vdc}^{*}$ for the STATCOM is proposed. The main features of the proposed STATCOM controller are summarized as follows:

1) MI can be kept constant at steady state for both inductive and capacitive reactive power (VAR) compensation conditions. As a result, the output voltage harmonics of the voltage-sourced inverter (VSI) and the output current harmonics of the STATCOM at steady state can be kept minimal.

2) Under inductive VAR compensation, the dc voltage is regulated at low level and the MI is held constant at unity. The need for narrow switching pulses as a result of low MI is avoided. As a result, the switching stresses on the semiconductor devices can be reduced.

3) During the transient of decreasing capacitive or increasing inductive VAR compensation, the controller can use a high dc voltage level to control both MI and phase angle to instantaneously generate the required reactive current. 


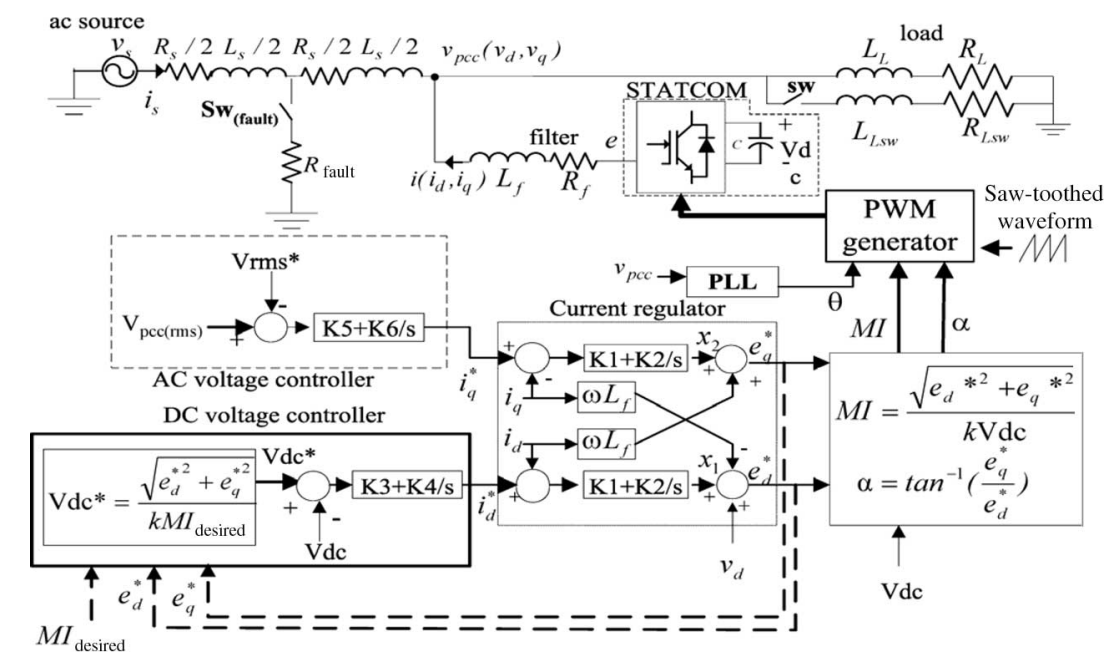

Fig. 1. Proposed STATCOM controller.

The contents of this paper are as follows. First, the architecture of the proposed STATCOM controller is described. Then, a systematic procedure for the design of the current regulator, the dc voltage controller, and the ac voltage controller is presented. To avoid the overshoot and oscillatory response in the current regulator loop, pole-zero cancellation technique is employed to get a first-order system in the current regulator loop. In addition, root-locus method and pole assignment technique are employed in the design of the dc voltage controller and ac voltage controller to shift dominant poles leftward such that faster dynamic responses can be achieved. Finally, simulation and experimental results are presented to demonstrate the steady-state performance and transient responses of the STATCOM with the proposed STATCOM controller. Based on these results, the inverter output voltage and current harmonics for the proposed STATCOM controller are compared with the conventional controller with fixed $\mathrm{Vdc}$ *

\section{PRoposed STATCOM CONTROLLER ARCHITECTURE}

To avoid the negative impact on harmonic contents caused by variable MI in the MI- $\alpha$ control scheme and to enhance the response speed of the $\alpha$ control scheme, a novel control scheme, in which both the magnitude $|E|$ as well as the phase angle $\alpha$ of the STATCOM output voltage are controlled, is depicted in Fig. 1. It is observed from the figure that the STATCOM is composed of a VSI and a dc capacitor C. The STATCOM is connected to the point of common coupling (PCC) at the ac system through a filter with resistance $R_{\mathrm{f}}$ and inductance $L_{\mathrm{f}}$. The PCC is supplied power from the ac source with source voltage $v_{\mathrm{s}}$ and source impedance $R_{\mathrm{s}}+j \omega L_{\mathrm{s}}$. The objective of the STATCOM is to generate a proper control signal $e=|E| \angle \alpha$ such that the ac bus voltage at PCC remains constant when there is a change in system load. The ac bus voltage at PCC, $v_{\text {pcc }}$, the STATCOM output voltage $e$, and output current $i$ are expressed in $d$ - and $q$-coordinates $\left(v_{d}, v_{q}, e_{d}, e_{q}, i_{d}\right.$, and $\left.i_{q}\right)$ in the synchronous reference frame [3].

As shown in Fig. 1, the proposed STATCOM controller comprises a current regulator, a dc voltage controller, and an ac voltage controller. The current regulator generates the desired STATCOM output voltages $e_{d}^{*}$ and $e_{q}^{*}$ based on the error current signals $\left(i_{d}^{*}-i_{d}\right)$ and $\left(i_{q}^{*}-i_{q}\right)$. The real current reference $i_{d}^{*}$ and the reactive current reference $i_{q}^{*}$ come from the dc voltage controller and the ac voltage controller, respectively. Note that a PWM controller instead of a hysteresis controller is adopted in this work since the switching frequency for a PWM controller is fixed and this feature makes the modeling and harmonic filter design for the inverter easier. Details on the design of the current regulator, the dc voltage controller, and the ac voltage controller are given in the next section.

It is also observed from Fig. 1 that a novel dc voltage controller is proposed to modulate the reference voltage $\mathrm{Vdc}^{*}$ for the dc capacitor. With the proposed dc voltage controller in Fig. 1, it is expected that, under steady-state situations, the dc capacitor voltage Vdc is equal to the steady-state reference voltage $\mathrm{Vdc}_{\text {(steady-state) }}^{*}$ and the MI is fixed at the value $\mathrm{MI}_{\text {desired }}$ as described below

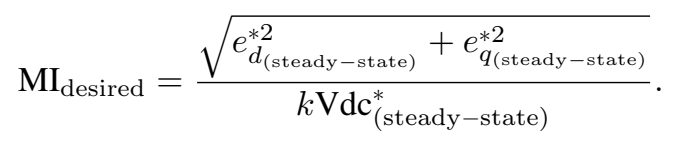

In this way, the advantage of minimal harmonics inherent in the $\alpha$ control scheme with fixed MI can be retained in the proposed STATCOM control scheme under steady-state situations. The negative impact on harmonic contents in the MI- $\alpha$ control scheme can thus be avoided by the proposed STATCOM control scheme. When there is a need to adjust the reactive power output during the transient period, the actual dc capacitor voltage no longer equals the steady-state reference voltage $\operatorname{Vdc}_{(\text {steady-state) }}^{*}$ as described below

$$
\mathrm{Vdc}_{(\text {steady-state })}^{*}=\frac{\sqrt{e_{d_{(\text {steady }- \text { state })}^{* 2}}^{*}+e_{q_{(\text {steady }- \text { state })}^{* 2}}}}{k \mathrm{MI}_{\text {desired }}}
$$

As a result, the MI deviates from the steady-state value $\mathrm{MI}_{\text {desired }}$. However, this deviation of the MI has little effect on steady-state harmonic contents since the transient lasts for only a very short period. With the adjustment of the reference voltage 
TABLE I

SySTEM PARAMETERS USED IN SIMULATIONS AND EXPERIMENTS

\begin{aligned} & \hline Fundamental frequency: $f=60 \mathrm{~Hz} \\ &$ Source voltage: $v_{s}=78 \mathrm{~V}_{\text {peak }}\left(110 V_{L L_{(r m s)}}\right) \\ &$ Source resistance: $R_{S}=0.7 \Omega \\ &$ Source inductance: $L_{S}=1.6 \mathrm{mH} \\ &$ Filter inductance: $L_{f}=0.01 \mathrm{H} \\ &$ Filter resistance: $R_{f}=0.4 \\ &$ Switching frequency: $f_{C}=1920 \mathrm{hz} \\ &$ DC capacitor capacitance: $C=2200 \mathrm{uF} \\ &$ Estimated inverter loss resistance: $R p=5000 \Omega \\ &$ Inductance of fixed RL load: $L_{L}=40 \mathrm{mH} \\ &$ Resistance of fixed RL load: $R_{L}=8.4 \Omega \\ &$ Inductance of switchable RL load: $L_{L s w}=35.5 \mathrm{mH} \\ &$ Resistance of switchable RL load: $R_{L s w}=7 \Omega \\ &$ Sampling frequency: $f_{S}=15360 \mathrm{~Hz} \\ &$ Fault resistance: $R_{\text {fault }}=7 \Omega \\ &$\hline\end{aligned}

TABLE II

System EIgENVALUeS AT Full LoAd AND $i_{q}^{*}=-5 \mathrm{~A}$

\begin{tabular}{|c|c|c|}
\hline $\begin{array}{l}\text { System with } \\
\text { STATCOM but } \\
\text { without controller }\end{array}$ & $\begin{array}{c}\text { System with } \\
\text { STATCOM and } \\
\text { without AC voltage } \\
\text { controller } \\
\begin{array}{l}K 1=40, \quad K 2=1608, \\
K 3=-0.01, \quad K 4=-4.8,\end{array}\end{array}$ & $\begin{array}{l}\text { System with } \\
\text { STATCOM and with } \\
\text { AC voltage controller } \\
\left(\begin{array}{l}K 1=40, \quad K 2=1608, \\
K 3=-0.01, \quad K 4=-4.8, \\
K 5=-0.01, \quad K 6=-10\end{array}\right)\end{array}$ \\
\hline $\begin{array}{c}-227 \pm j 377 \\
-85 \pm j 377 \\
-0.187\end{array}$ & $\begin{array}{l}-223 \pm j 377 \\
-3500,-2180 \\
-40.1,-40.0 \\
-4.63 \pm j 33\end{array}$ & $\begin{array}{c}-223 \pm j 377 \\
-3500,-2180 \\
-40.1,-40.0 \\
-4.5 \pm j 31.1 \\
-6.47\end{array}$ \\
\hline
\end{tabular}

$\mathrm{Vdc}^{*}$ by the proposed dc voltage controller during the transient period, the STATCOM output voltage $|E|$ and reactive power $Q$ can be modulated in a very rapid manner. It is expected that the proposed STATCOM control scheme would respond faster than the conventional $\alpha$ control scheme where the fixed MI limits the response speed.

\section{Design of the Statcom Controller}

In Fig. 1, the STATCOM is controlled to deliver either inductive or capacitive currents from the power system by varying its output voltages $e_{a}, e_{b}$, and $e_{c}$, which can be transformed to be $e_{d}$ and $e_{q}$ in the synchronous reference frame [3]. The parameters for the system under study are listed in Table I in Appendix I-A.

To determine the proper parameters for the current regulator, the dc voltage controller and the ac voltage controller, the nonlinear equations of the study system are linearized around a nominal operating condition and the resulting linearized state equation is given by

$$
\begin{aligned}
& \dot{X}(t)=A X(t)+B U(t) \\
& Y(t)=C X(t)
\end{aligned}
$$

where $X(t)=\left[\begin{array}{lllll}i_{\mathrm{s} d} & i_{\mathrm{s} q} & i_{d} & i_{q} & v_{\mathrm{dc}}\end{array}\right]^{\mathrm{T}}$ is the state vector, $U(t)$ is the input vector and $Y(t)$ is the output vector. Then, the eigenvalues for the system with STATCOM but without any STATCOM controller can be computed and are listed in column 1 of Table II in Appendix I-B. Note that the STATCOM outputs $e_{d}$ and $e_{q}$ remain constant in this case. It is observed from Table II that the STATCOM mode (characterized by the pair of eigenvalues $-85 \pm j 377$ ) has less damping than the others and the eigenvalues for this mode should be shifted leftward to more desirable locations by a STATCOM controller.

The STATCOM controller design begins with the determination of the gains $K 1$ and $K 2$ for the current regulator using pole-zero cancellation. Then the gains $K 3$ and $K 4$ for the dc voltage controller are determined using pole assignment technique. This is followed by the determination of the gains $K 5$ and $K 6$ for the ac voltage controller using pole assignment technique. It may be necessary to repeat the procedures for the dc voltage controller and the ac voltage controller until satisfactory ac bus voltage dynamic performance is reached. Details on the design of these controllers are described below.

1) Design of the Current Regulator: To determine $K 1$ and $K 2$, the closed-loop transfer functions for $d$-axis current and $q$-axis current of the STATCOM connected to the PCC can be written in the $d-q$ synchronous frame as follows [3], [17]:

$$
G_{\mathrm{C}}(s)=\frac{i_{q}(s)}{i_{q}^{*}(s)}=\frac{i_{d}(s)}{i_{d}^{*}(s)}=\frac{s K 1+K 2}{L_{\mathrm{f}} s^{2}+\left(R_{\mathrm{f}}+K 1\right) s+K 2} .
$$

To avoid the overshoot and oscillatory responses for the second-order system in (5), pole-zero cancellation is performed by using the following relationship between $K 2$ and $K 1$ :

$$
K 2=\frac{R_{\mathrm{f}}}{L_{\mathrm{f}}} K 1
$$

After (6) is substituted into (5), a first-order closed-loop transfer function for the current regulator can be obtained

$$
G_{\mathrm{c}}(s)=\frac{i_{q}(s)}{i_{q}^{*}(s)}=\frac{i_{d}(s)}{i_{d}^{*}(s)}=\frac{K 1 / L_{\mathrm{f}}}{s+K 1 / L_{\mathrm{f}}} .
$$

It is observed from (7) that the crossover frequency $\omega_{\text {crossover }}$ for the closed loop transfer function of the current regulator is given by

$$
\omega_{\text {crossover }}=\frac{K 1}{L_{\mathrm{f}}} .
$$

This is a very stable system with $90^{\circ}$ of phase margin. In practical implementation, the crossover frequency $\omega_{\text {crossover }}$ is limited by the PWM carrier frequency $\omega_{\mathrm{c}}=2 \pi f_{\mathrm{c}}$. The values of $K 1$ and $K 2$ used in this paper are given in Appendix I-C.

2) Design of the DC Voltage Controller: The reference for the real current, $i_{d}^{*}$, is derived from a PI controller as described in (9) such that the dc capacitor voltage Vdc follows the reference value $\mathrm{Vdc}^{*}$ :

$$
i_{d}^{*}=\left(K 3+\frac{K 4}{s}\right)\left(\mathrm{Vdc}^{*}-\mathrm{Vdc}\right) .
$$

After the pair of controller gains $K 1=40$ and $K 2=1608$ have been determined for the current regulator, we proceed to determine the gains $K 3$ and $K 4$ for the dc voltage controller. The reference value for the reactive current, $i_{q}^{*}$, is fixed at the rated current $(-5 \mathrm{~A})$ and the system is operated under full load condition with the load switch SW in Fig. 1 closed is assumed. Fig. 2 depicts the root loci for the eigenvalues associated with the critical mode for various combinations of the parameters 


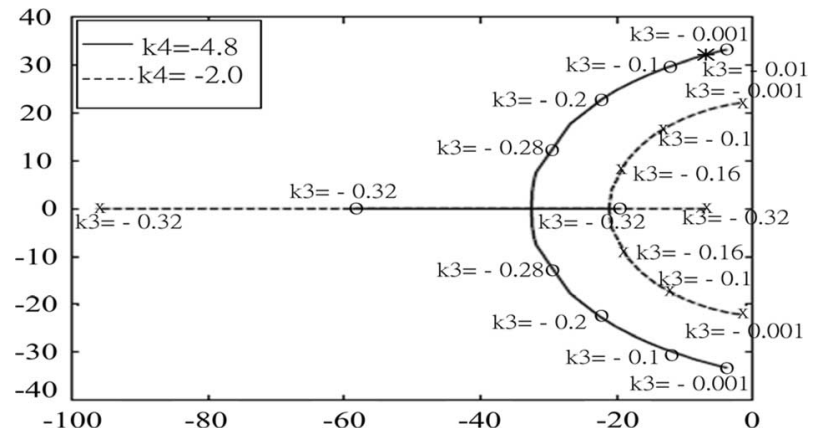

Fig. 2. Root loci for the STATCOM with de voltage controller only $\left(i_{q}^{*}\right.$ is fixed).

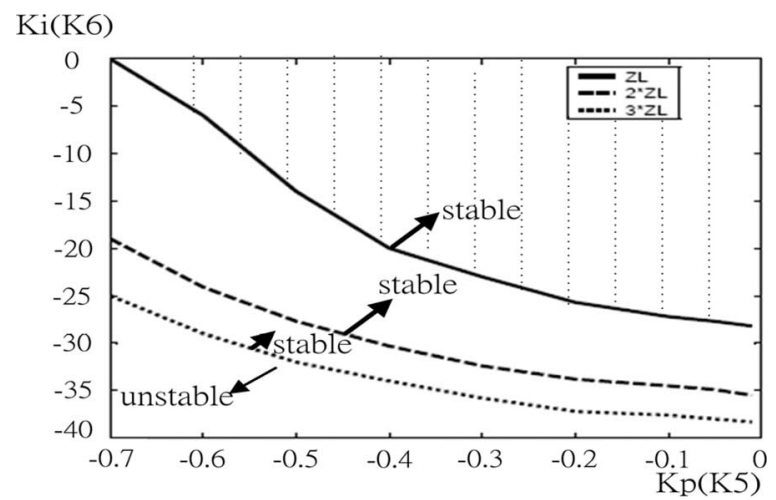

Fig. 3. Stable regions for PI controller gains $K 5$ and $K 6$ under different loading conditions.

$K 3$ and $K 4$. A proper pair of gains can be determined based on the consideration of enough phase margin, good damping, and fast response. Satisfactory response is achieved by the system with the controller gains $K_{3}=-0.01$ and $K_{4}=-4.8$ where the eigenvalues for the critical mode have been moved to the location $-4.63 \pm j 33$. Note that the eigenvalues cannot be moved too far into the left hand plane to avoid excessive large capacitor charging currents [13]. The eigenvalues of the system with STATCOM and without an ac voltage controller are listed in column 2 of Table II. It is observed from Table II that the eigenvalues for the STATCOM mode have been moved from $-85 \pm j 377$ to -3500 and -2180 with a first-order system response without overshoots after the values of $K 1$ and $K 2$ are determined by pole-zero cancellation method mentioned earlier.

3) Design of the AC Voltage Controller: The reference value for the reactive current, $i_{q}^{*}$, is derived from a PI controller described in (10) such that the ac bus voltage $V_{\mathrm{pcc}(\mathrm{rms})}$ follows the preset value Vrms*

$$
i_{q}^{*}=\left(K 5+\frac{K 6}{\mathrm{~s}}\right)\left(\mathrm{Vrms}^{*}-V_{\mathrm{pcc}(\mathrm{rms})}\right) .
$$

With a fixed ac voltage reference of $53 \mathrm{~V}$, the stable regions for PI controller gains $K 5$ and $K 6$ under different loading conditions are depicted in Fig. 3. It is obvious from Fig. 3 that the smallest stable region is observed for PI controller gains $K 5$ and $K 6$ when the system is operated under full load condition (load impedance equals $Z_{\mathrm{L}}$ ). When the load is reduced (load impedance is doubled or tripled to $2 Z_{\mathrm{L}}$ or $3 Z_{\mathrm{L}}$ ),

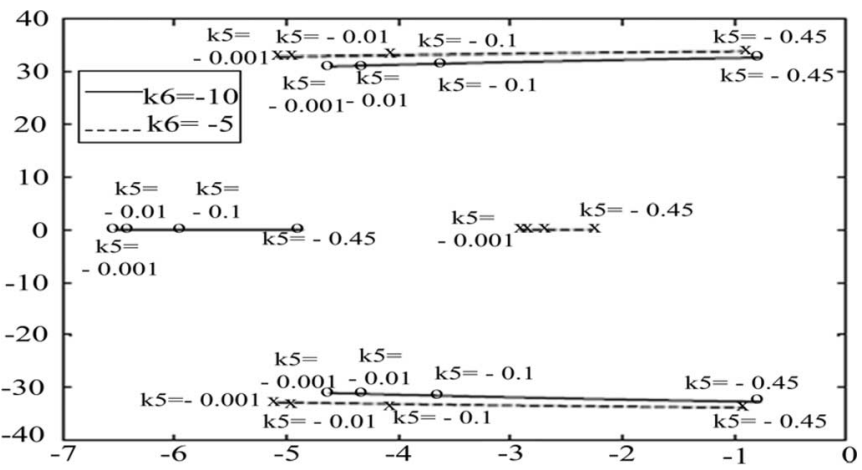

Fig. 4. Root loci for the STATCOM with both de voltage controller and ac voltage controller (Vrms* is fixed).

the stable region for the gains $K 5$ and $K 6$ expands. Thus, the PI controller gains $K 5$ and $K 6$ will be designed based on the system under full load condition. The design procedures for $K 5$ and $K 6$ are similar to those for $K 3$ and $K 4$ described earlier. Fig. 4 depicts the root loci for the STATCOM with the ac voltage controller. It is found that the pair of gains $K 5=-0.01$ and $K 6=-10$ for the ac voltage controller gives satisfactory dynamic response. The gain margin and the phase margin of the closed-loop system are $1.33 \mathrm{~dB}$ and $-14.8^{\circ}$, respectively. The eigenvalues of the closed-loop system with the designed current regulator, dc voltage controller, and ac voltage controller are summarized in the third column of Table II. It is observed from the eigenvalues in Table II that, with the incorporation of the ac voltage controller, the eigenvalues for the STATCOM mode $(-3500$ and -2180$)$ remain unchanged and the critical eigenvalues $(-4.63 \pm j 33)$ have been moved only a little to the new locations $(-4.5 \pm j 31.1)$.

\section{Simulation Results}

To examine the effectiveness of the proposed STATCOM controller with fixed modulation and variable $\mathrm{Vdc}^{*}$, the system in Fig. 1 was simulated using Matlab/Simulink and the results are presented in Figs. 5 and 6. Note that the system parameters used in the simulation are the same as those used in the experiments as described in Table I. Both steady-state performance and dynamic responses were investigated. The main purpose for the simulations and the experiments to be described in the next section is to show that fast dynamic responses can be reached by the proposed STATCOM controller with lower harmonic voltages and currents than the conventional method with fixed $\mathrm{Vdc}^{*}$ at steady state.

\section{A. Steady-State Harmonic Performance}

The steady-state response curves for the STATCOM with the proposed STATCOM control scheme and with the conventional method with fixed $\mathrm{Vdc}^{*}$ are compared in Fig. 5. In the simulations, the STATCOM was operated either at rated capacitive $\operatorname{VAR}\left(i_{q}^{*}=-5 \mathrm{~A}\right)$ or at rated inductive $\operatorname{VAR}\left(i_{q}^{*}=5 \mathrm{~A}\right)$. Only the results for capacitive VAR compensation condition are presented due to limited space. It is observed from the curves in Fig. 6(b) that the dc capacitor voltage was fixed at a high level of $250 \mathrm{~V}$ and the MI was 0.7 for the conventional controller. This is as expected since a lower MI is needed for a lower 


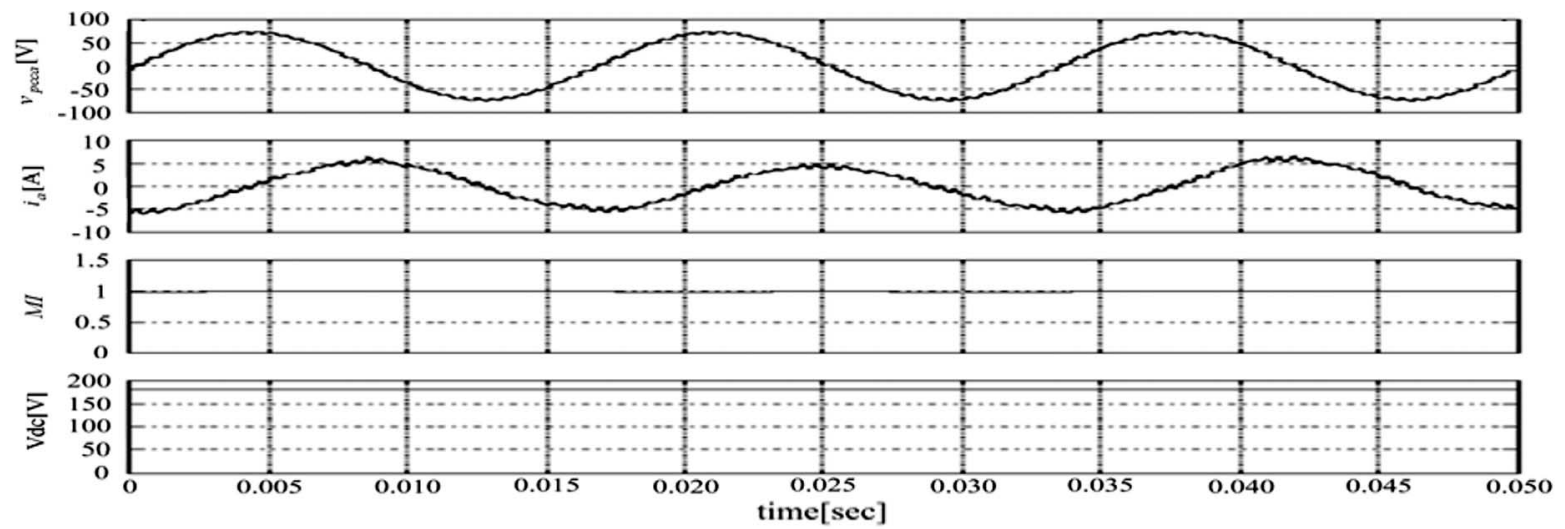

(a)

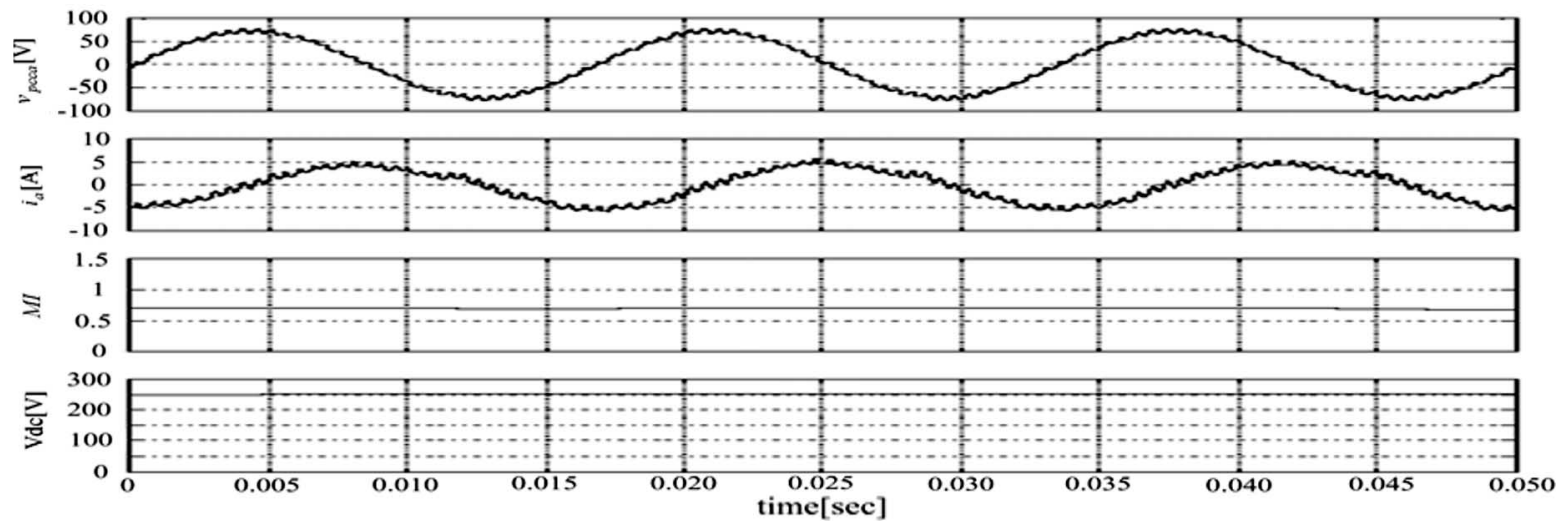

(b)

Fig. 5. Steady-state simulation results. (a) Capacitive VAR compensation condition using the proposed STATCOM controller (fixed MI and variable Vdc*). (b) Capacitive VAR compensation condition using the conventional controller (fixed Vdc $\left.{ }^{*}\right)\left(v_{p c c a}\right.$ : PCC phase A voltage, $i_{a}$ : STATCOM phase output current, MI: modulation index, Vdc: dc capacitor voltage).

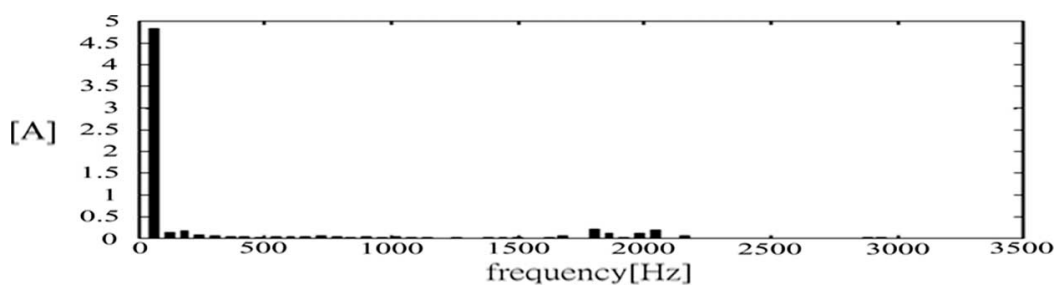

(a)

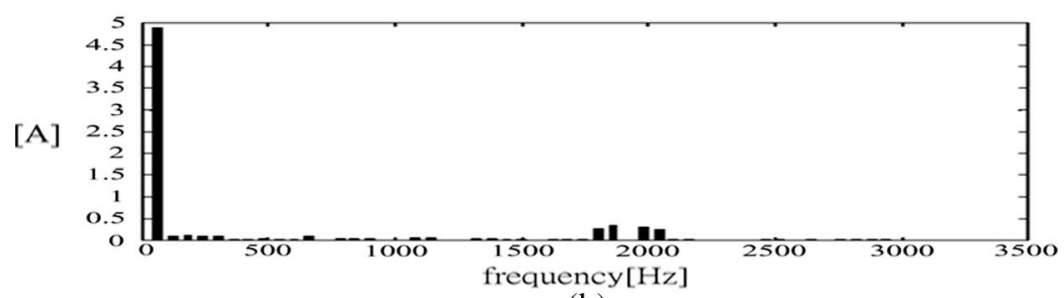

(b)

Fig. 6. Harmonic spectrum of STATCOM phase A output current $\left(i_{a}\right)$ from Steady-state simulation. (a) Capacitive VAR compensation condition using the proposed STATCOM controller (fixed MI and variable Vdc ${ }^{*}$ ). (b) Capacitive VAR compensation condition using the conventional controller (fixed Vdc ${ }^{*}$ ).

STATCOM output voltage in the capacitive VAR compensation case as $\mathrm{Vdc}^{*}$ is fixed in the conventional controller. This lower MI may cause higher harmonic contents as shown in Fig. 6(b). On the other hand, the MI in the proposed controller remained constant at unity and Vdc was at a lower level of $185 \mathrm{~V}$ when the STATCOM was operated under capacitive VAR compensation condition and required a lower output voltage. Since the MI remains fixed at unity, the harmonic contents for the proposed
STATCOM controller in Fig. 6(a) is much lower than those for the conventional controller in Fig. 6(b).

\section{B. Dynamic Responses}

It has been demonstrated in Fig. 6 that the proposed STATCOM controller with fixed MI gives better harmonic performance than the conventional controller with fixed $\mathrm{Vdc}^{*}$ 


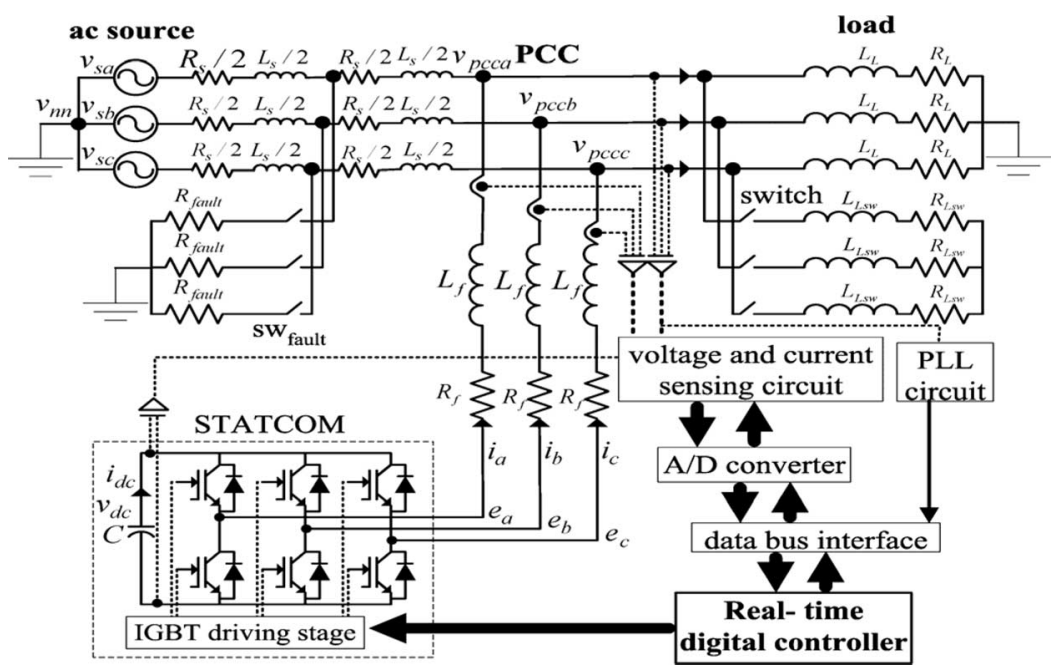

Fig. 7. Experimental setup for a prototype STATCOM.

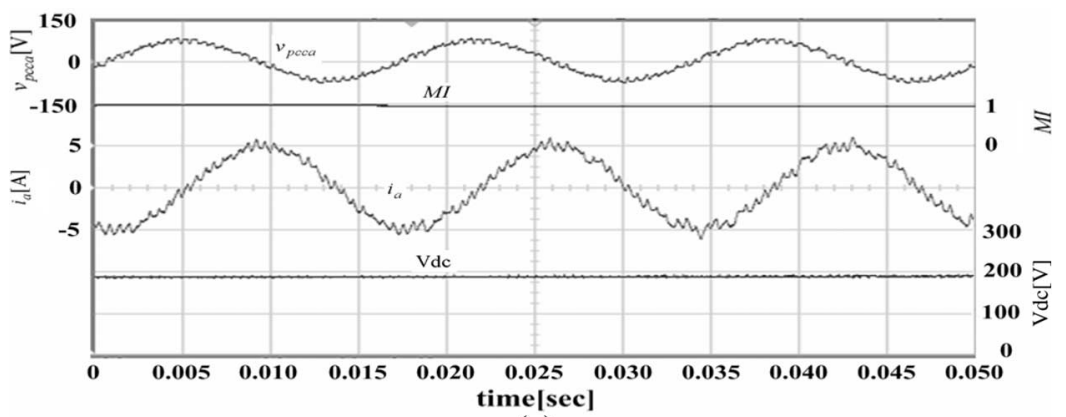

(a)

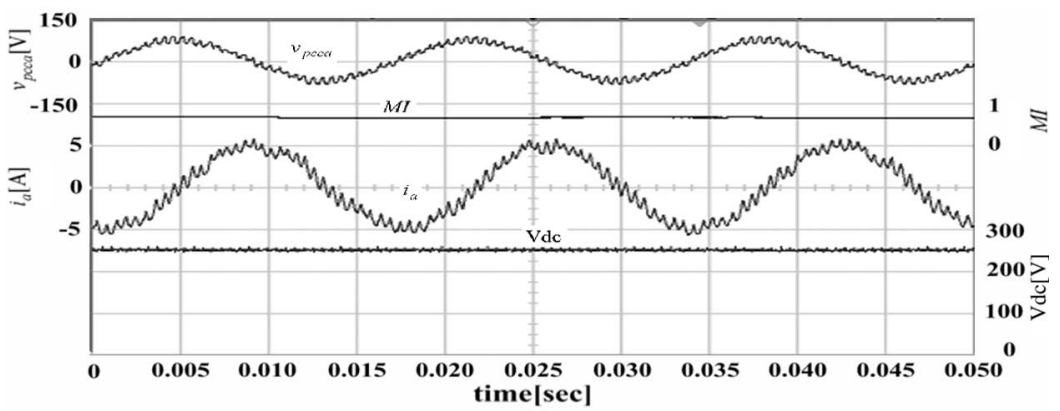

(b)

Fig. 8. Steady-state experimental results. (a) Capacitive VAR compensation condition using the proposed STATCOM controller (fixed MI and variable Vdc*). (b) Capacitive VAR compensation condition using the conventional controller (fixed Vdc $\left.{ }^{*}\right)\left(v_{p c c a}\right.$ : PCC phase A voltage, MI: modulation index, $i_{a}$ : STATCOM phase A output current, Vdc: dc capacitor voltage).

at steady state. To examine the dynamic performance of the proposed STATCOM controller, the system was simulated under a step change in $i_{q}^{*}$, a three-phase line to neutral fault, and a step load change. The dynamic response curves from these simulations are similar to those from the experiments. Because of limited space, the simulation results from dynamic tests are not shown here and detailed discussions on the dynamic responses will be made in the next section using the experimental results in Fig. 11.

\section{EXPERIMENTAL RESUlTS}

A prototype $5 \mathrm{kVA}$ STATCOM for a simple power distribution system has been implemented at the laboratory. Fig. 7 shows the experimental setup. The system consists of an ac voltage source with voltage $v_{\mathrm{s}}$, two impedance loads (one is fixed and the other is connected to the PCC through a switch) that draw lagging current, and a STATCOM that generates reactive current to control PCC bus voltage. The STATCOM is composed of a VSI and a dc capacitor. The STATCOM control hardware comprises a PLL circuit, a voltage and current sensing circuit, an A/D converter module, and a real-time digital controller module. The parameters of the system have been given in the Table I of Appendix I-A. Figs. 8-11 depict the results from experiments.

\section{A. Steady-State Harmonic Performance}

By comparing the response curves in Fig. 8 from experiments and the results in Fig. 5 from simulations, it is obvious 


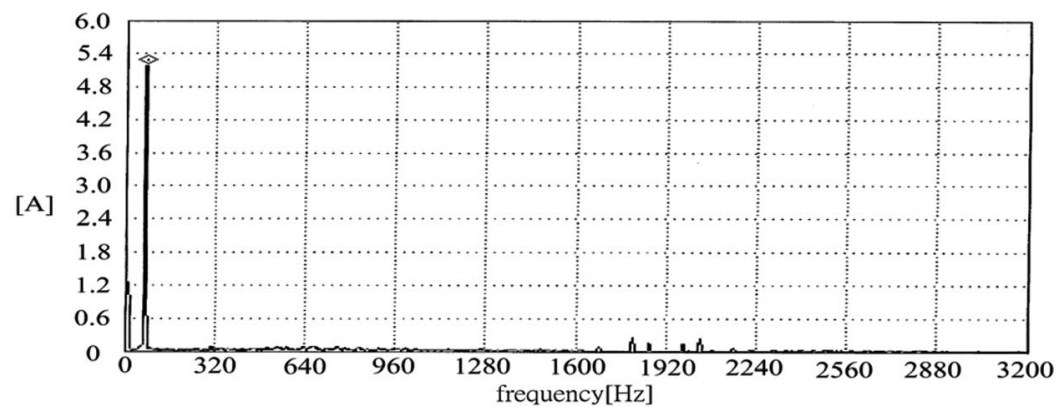

(a)

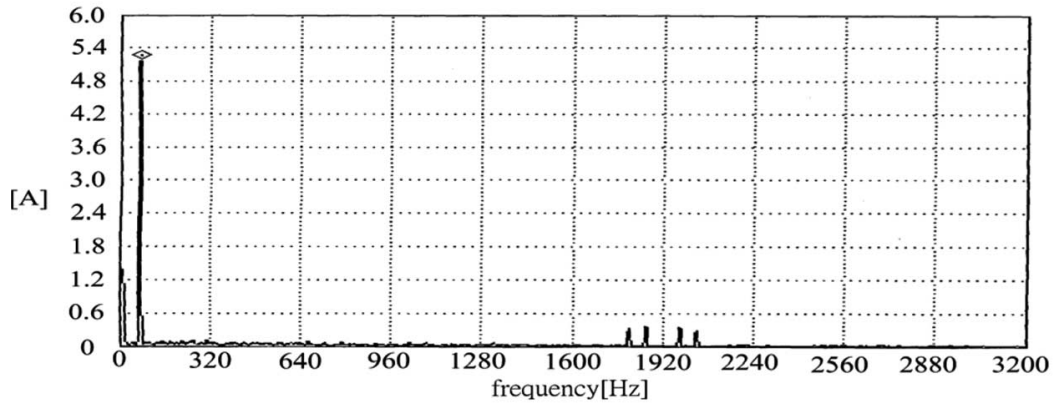

(b)

Fig. 9. Harmonic spectrum of STATCOM phase A output current $\left(i_{a}\right)$ from steady-state experiments. (a) Capacitive VAR compensation condition using the proposed STATCOM controller (fixed MI and variable Vdc*). (b) Capacitive VAR compensation condition using the conventional controller (fixed Vdc*).

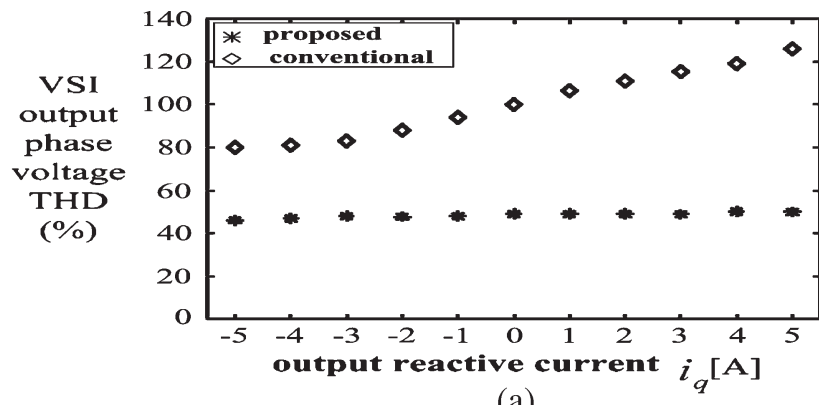

(a)

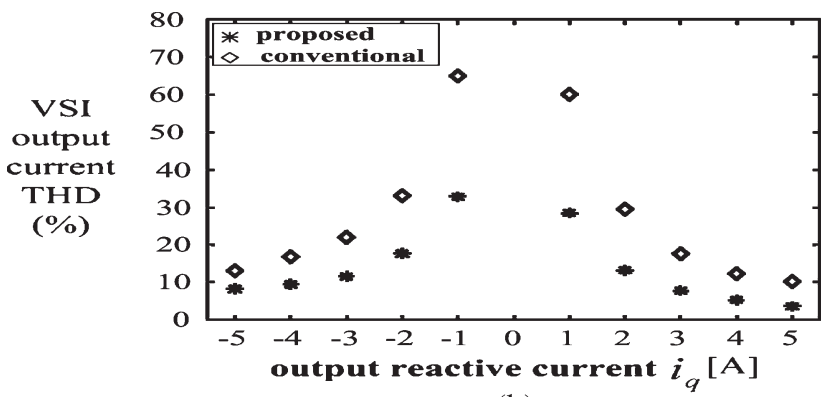

(b)

Fig. 10. Comparison of the THDs from steady-state experiments using the proposed STATCOM controller (fixed MI and variable Vdc*) and the conventional controller (fixed $\mathrm{Vdc}^{*}$ ). (a) STATCOM output phase voltage THDv. (b) STATCOM output current THDi.

that the experimental results are close to the simulation results. Therefore, the conclusions that have been made with regard to simulation results apply equally well to the experimental results and will not be repeated. It is worth noting that the $\mathrm{dc}$ capacitor voltage reference $\mathrm{Vdc}^{*}$ was fixed at $250 \mathrm{~V}$ in the conventional controller while the MI was fixed at unity in the proposed controller in both simulation and experiments.

To compare the steady-state performance of the proposed STATCOM control method with fixed MI and the conventional control method with fixed $\mathrm{Vdc}^{*}$, the total harmonic distortions for inverter output voltage $(e)$ and inverter output current $(i)$ are shown in Fig. 10. It is found that the proposed STATCOM control method generates lower THDv and THDi than the conventional control scheme over the entire operational range. The reduction of THDv by the proposed STATCOM controller is more significant when the STATCOM is operated in the inductive load VAR compensation condition (for example, $V_{\mathrm{dc}}=103 \mathrm{~V}, \mathrm{MI}=1.0$ for the proposed STATCOM controller and $V_{\mathrm{dc}}=250 \mathrm{~V}, \mathrm{MI}=0.4$ for the conventional controller while $i_{q}^{*}=5 \mathrm{~A}$ ), as shown in Fig. 10(a). It is also observed from Fig. 10(b) that the THDi of the output current from the proposed STATCOM controller is less than that from the conventional controller. Note that THDi is undefined when the output reactive fundamental current is close to zero.

To make the STATCOM effective for the system operated at either capacitive or inductive compensation condition, the $\mathrm{dc}$ capacitor voltage reference $\mathrm{Vdc}^{*}$ must be maintained at a sufficiently high level. Keeping the dc voltage constant simplifies the voltage control scheme, but increases the switching stress. The high stress is more significant when the STATCOM is operated under inductive reactive power compensation situation since the low MI causes narrow pulses from the PWM comparing circuit. The high stress problem can be relieved by using the proposed STATCOM control scheme where the dc voltage reference changes with the reactive power demand and the possibility of narrow switching pulses resulting from 


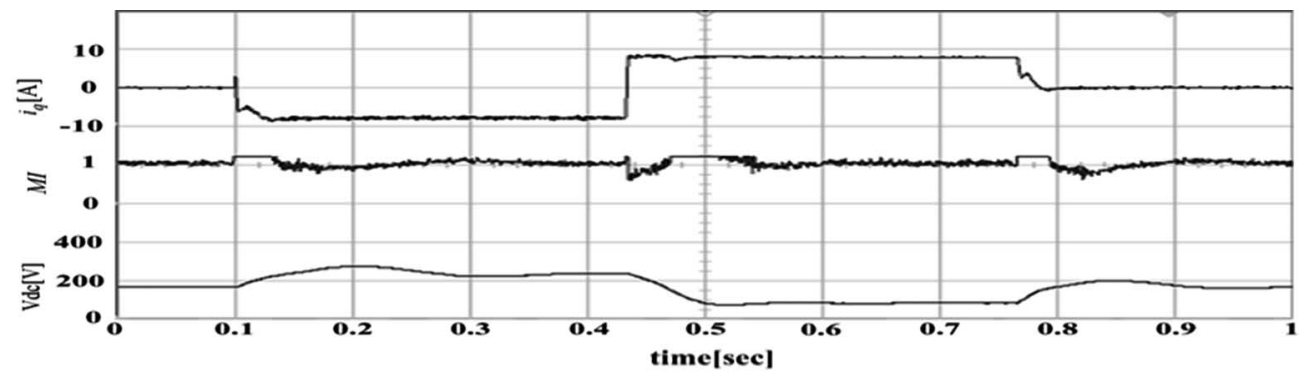

(a)

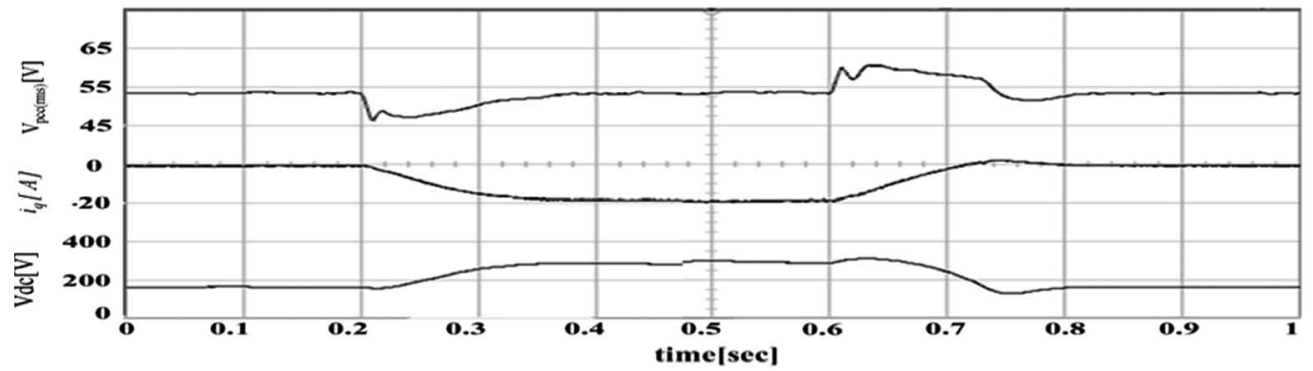

(b)

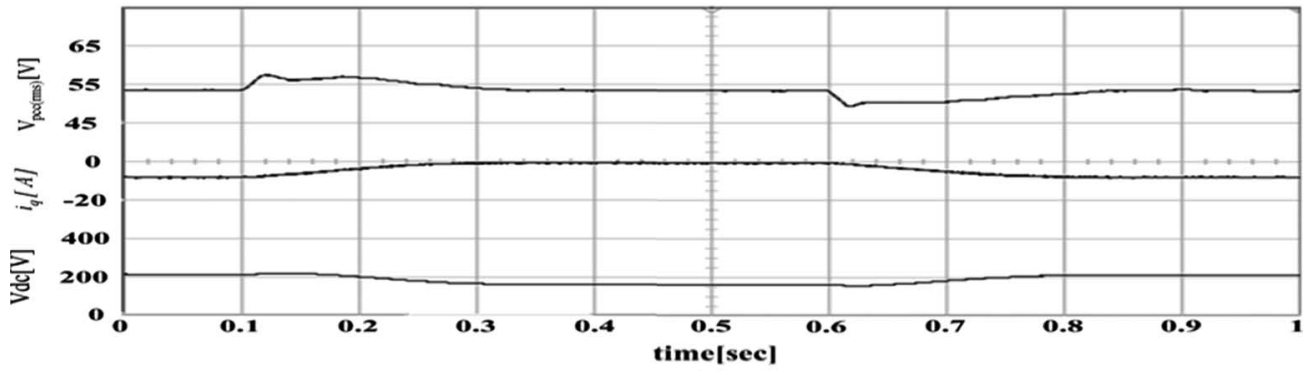

(c)

Fig. 11. Dynamic responses from experiments using the proposed STATCOM controller. (a) For a step change in $i_{q}^{*}$ from -8 to 8 A. (b) For a three-phase line to neutral fault (the period of the fault is from $t=0.2 \mathrm{~s}$ to $t=0.6 \mathrm{~s}$ ). (c) For a load change (the switchable load impedance $R_{\mathrm{Lsw}}+j \omega L_{\mathrm{Lsw}}$ is switched off at $t=0.1 \mathrm{~s}$ and on at $t=0.6 \mathrm{~s})\left(i_{q}\right.$ : STATCOM output reactive current, MI: modulation index, Vdc: dc capacitor voltage, $V_{\mathrm{pcc}}(\mathrm{rms})$ : the root-mean-square value of PCC bus voltage).

low MI is reduced. Since the MI can be fixed at unity which gives minimal inverter output voltage harmonics at steady state under all possible reactive power demands, the switching pattern for the proposed STATCOM control scheme is composed of wider pulses and the resulting switching stresses are lower.

\section{B. Dynamic Response}

To examine the dynamic performance of the proposed STATCOM controller, the system was tested under a step change in $i_{q}^{*}$, a three-phase line to neutral fault, and a step load change. Fig. 11 depicts the results from these experiments.

1) Step Change in $i_{q}^{*}$ : The dynamic response curves for the system operated under full load (load switch SW is switched on) and with the proposed STATCOM controller are depicted in Fig. 11(a), when there was a step change in the reference value for the quadrature axis current (reactive current) $\left(i_{q}^{*}\right)$. It is observed from Fig. 11(a) that, in response to a step change from -8 to $8 \mathrm{~A}$ in $i_{q}^{*}$, the reactive current $i_{q}$ settles in $10 \mathrm{~ms}$. Immediately after the step input, the MI changed to values somewhat larger than unity but soon settled to the steady-state value of unity. The dc capacitor voltage settled to a new value that is higher than the original one to give higher STATCOM output voltage and deliver more reactive current.

2) Three-Phase Line to Neutral Fault: When there was a fault from $t=0.2 \mathrm{~s}$ to $t=0.6 \mathrm{~s}$, the PCC bus voltage dipped to a lower level of $47 \mathrm{~V}$ (about 10\%) for the system without STATCOM. The dynamic response curves for the system with STATCOM are depicted in Fig. 11(b). It is observed that the PCC bus voltage $V_{\mathrm{pcc}(\mathrm{rms})}$ recovered to the reference value of $53 \mathrm{~V}$ within $170 \mathrm{~ms}$ with an overshoot of $8 \mathrm{~V}$. In this case, $i_{q}$ changed from -0.5 to $-20 \mathrm{~A}$ and $\mathrm{Vdc}$ increased from 136 to $295 \mathrm{~V}$ in about $170 \mathrm{~ms}$.

3) Step Load Change: The dynamic response curves are depicted in Fig. 11(c) when the switchable load impedance $R_{\mathrm{Lsw}}+j \omega L_{\mathrm{sw}}$ was switched off at $t=0.1 \mathrm{~s}$ and switched on at $t=0.6 \mathrm{~s}$. It is observed from the response curves in Fig. 11(c) that the ac bus voltage $V_{\mathrm{pcc}(\mathrm{rms})}$ settled to the reference value of Vrms $^{*}=53$ in about $170 \mathrm{~ms}$ with an overshoot of $4 \mathrm{~V}$ when the load impedance was switched off at $100 \mathrm{~ms}$. In addition, both the reactive current $i_{q}$ and dc capacitor voltage $\mathrm{Vdc}$ settled to new values in about $170 \mathrm{~ms}$. It is noted that neither overshoots 
nor oscillatory responses are observed in Fig. 11. This is as expected since the current regulator has been designed based on pole-zero cancellation to achieve first-order system response without overshoots and oscillations.

\section{CONCLUSION}

A novel control scheme with fixed MI and variable dc capacitor voltage reference has been proposed for a STATCOM that is used to provide reactive power compensation and regulate ac system bus voltage. A systematic approach based on polezero cancellation has been developed for the current regulator in the STATCOM to achieve first-order system response without overshoots and oscillations in the real current $\left(i_{d}\right)$ and reactive current $\left(i_{q}\right)$. To have fast transient responses for the STATCOM, root-locus method and pole assignment technique have been employed in the design of the dc voltage controller and ac voltage controller such that the dominant poles are shifted leftward. The effectiveness of the proposed STATCOM controller has been demonstrated by steady state and transient response curves from both simulations and experiments. A major feature of the proposed dc voltage controller is that the MI is held constant at steady state for both inductive and capacitive reactive power compensation situations. Thus, lower harmonic voltages and currents can be achieved by the proposed STATCOM controller than the conventional controller with fixed dc capacitor voltage and variable MI. In the case of inductive VAR compensation, the dc voltage is regulated at a low level and the MI is held constant at unity. The need for narrow switching pulses as a result of low MI is avoided and the switching stresses on the semiconductor devices can be reduced. During the transient of decreasing capacitive and increasing inductive reactive power compensation, the controller can use high dc voltage to control both MI and phase angle to generate the required reactive current in a very efficient manner. In addition, the proposed STATCOM controller with parameters designed using the proposed approach has good dynamic responses in the reactive current reference step change testing, ac bus voltage regulation testing under a three-phase line to neutral fault, and a step load change testing.

\section{APPENDIX I}

\section{A. System Parameters}

See Table I.

\section{B. System Eigenvalues}

See Table II.

\section{Calculation of $K 1$ and $K 2$}

In this paper, the crossover frequency $\omega_{\text {crossover }}$ is set as

$$
\omega_{\text {crossover }}=\frac{1}{3} \omega_{\mathrm{c}}=\frac{1}{3} \cdot 2 \pi f_{\mathrm{c}} .
$$

The inverter switching frequency $f_{\mathrm{c}}$ used in this work is $1920 \mathrm{~Hz}$. From (8) and (6), K1 and $K 2$ can be calculated as follows:

$$
\begin{aligned}
\omega_{\text {crossover }} & =\frac{K 1}{L_{\mathrm{f}}}=\frac{1}{3} \cdot 2 \pi \cdot 1920=4021 \\
K 1 & =\omega_{\text {crossover }} \cdot L_{\mathrm{f}}=40.21 \\
K 2 & =\frac{R_{\mathrm{f}}}{L_{\mathrm{f}}} \cdot K 1=\frac{0.4}{0.01} * 40.21=1608.4 .
\end{aligned}
$$

\section{REFERENCES}

[1] C. Schauder, M. Gernhardt, E. Stacey, T. Lemak, L. Gyugyi, T. W. Cease, and A. Edris, "Operation of \pm 100 MVAr TVA STATCON," IEEE Trans. Power Del., vol. 12, no. 4, pp. 1805-1811, Oct. 1997.

[2] B. Singh, S. S. Murthy, and S. Gupta, "STATOM-based voltage regulator for self-excited induction generator feeding nonlinear loads," IEEE Trans. Ind. Electron., vol. 53, no. 5, pp. 1437-1452, Oct. 2006.

[3] C. Schauder and H. Mehta, "Vector analysis and control of advanced static VAr compensators," Proc. Inst. Electr. Eng.-Generation, Transmission, Distribution, vol. 140, no. 4, pp. 299-306, Jul. 1993.

[4] C. T. Chang and Y. Y. Hsu, "Design of UPFC controllers and supplementary damping controller for power transmission control and stability enhancement of a longitudinal power system," Proc. Inst. Electr. Eng.-Generation, Transmission, Distribution, vol. 149, no. 4, pp. 463 471, Jul. 2002.

[5] B.-S. Chen and Y. Y. Hsu, "An analytical approach to harmonic analysis and controller design of a STATCOM," IEEE Trans. Power Del., vol. 22, no. 1, pp. 423-432, Jan. 2007.

[6] L. T. Moran, P. D. Ziogas, and G. Joos, "Analysis and design of a threephase synchronous solid-state VAr compensator," IEEE Trans. Ind. Appl., vol. 25, no. 4, pp. 598-608, Jul./Aug. 1989.

[7] G. Joos, L. T. Moran, and P. D. Ziogas, "Performance analysis of a PWM inverter VAr compensator," IEEE Trans. Power Electron., vol. 6, no. 3 , pp. 380-391, Jul. 1991.

[8] X. Fu, J. Wang, and Y. Ji, "A novel STATCOM based on cascaded threephases voltage source inverter," in Proc. 32th Annu. IECON, Nov. 2006, pp. 2174-2179.

[9] P. Garica-Gonzalez and A. Garia-Cerrada, "Control system for a PWMbased STATCOM," IEEE Trans. Power Del., vol. 15, no. 4, pp. 1252 1257 , Oct. 2000.

[10] H. Johan and S. V. Frederik, "Voltage harmonics generated by voltage-fed inverters using PWM natural sampling," IEEE Trans. Power Electron., vol. 3, no. 3, pp. 297-302, Jul. 1988.

[11] V. Salehi, S. Afsharnis, and S. Kahrobaee, "Improvement of voltage stability in wind farm connection to distribution network using FACTS devices," in Proc. 32th Annu. IECON, Nov. 2006, pp. 4242-4247.

[12] Z. Chen, F. Blaabjerg, and Y. Hu, "Stability improvement of wind turbine systems by STATCOM," in Proc. 32th Annu. IECON, Oct. 2006, pp. 4213-4218.

[13] P. W. Lehn and M. R. Iravani, "Experimental evaluation of STATCOM closed loop dynamics," IEEE Trans. Power Del., vol. 13, no. 4, pp. 13781384, Oct. 1998

[14] S. Mohagheghi, Y. del Valle, G. K. Venayagamoorthy, and R. G. Harley, "A proportional-integrator type adaptive critic design-based neurocontroller for a static compensator in a multimachine power system," IEEE Trans. Ind. Electron., vol. 54, no. 1, pp. 86-96, Feb. 2007.

[15] P. S. Sensarma, K. R. Padiyar, and V. Ramanarayanan, "Analysis and performance evaluation of a distribution STATCOM for compensating voltage fluctuations," IEEE Trans. Power Del., vol. 16, no. 2, pp. 259264, Apr. 2001.

[16] Y. Cheng, C. Qian, M. L. Crow, S. Pekarek, and S. Atcitty, "A comparison of diode-clamped and cascaded multilevel converters for a STATCOM with energy storage," IEEE Trans. Ind. Electron., vol. 53, no. 5, pp. 1512 1521, Oct. 2006.

[17] I. Papic, P. Zunko, D. Povh, and M. Weinhold, "Basic control of unified power flow controller," IEEE Trans. Power Syst., vol. 12, no. 4, pp. 1734 1739, Nov. 1997.

[18] A. R. Bergen and V. Vittal, Power System Analysis, 2nd ed. Englewood Cliffs, NJ: Prentice-Hall, 2000.

[19] N. Mohan, T. M. Undeland, and W. P. Robbins, Power Electronics: Converter, Applications, and Design. New York: Wiley, 1994. 


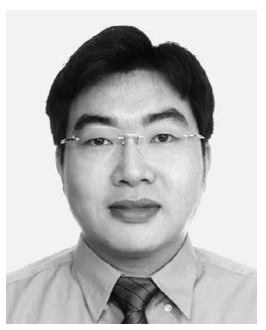

Ben-Sheng Chen received the B.S. degree from the National Chiao Tung University, Hsinchu, Taiwan, R.O.C., in 1998, and the M.S.E.E. and Ph.D. degrees from the National Taiwan University, Taipei, Taiwan, in 2000 and 2006, respectively.

$\mathrm{He}$ is now a Staff Engineer with Delta Electronics, Inc., Taipei. His areas of research interest include power electronics, power quality, modern control, and power system analysis.

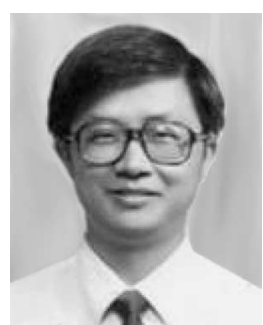

Yuan-Yih Hsu (S'82-M'82-SM'89) was born in Taiwan, R.O.C., on June 19, 1955. He received the B.S., M.S., and Ph.D. degrees in electrical engineering from National Taiwan University, Taipei, Taiwan

Since 1977, he has been with the National Taiwan University, where he is now a Professor. He was elected as one of the Ten Outstanding Young Engineers by the Chinese Institute of Engineers in 1989. At present, his research interests include reactive power compensation and the application of power electronics to power systems.

Dr. Hsu received Distinguished Research Awards from the National Science Council in 1986-1995. 